the "road machine" was shown in action; this machine having been designed to reduce the time necessary to test road materials from many months down to a corresponding number of hours. The machine was only completed a few weeks ago, but the few tests already made on improved road surfaces have already directed attention to several interesting phenomena which had long been suspected by road engineers, but were incapable or difficult of proof on the ordinary roadway on account of the great variations in weather, traffic, and other matters which render accurate comparative tests difficult, if not impossible.

\section{OPENING OF THE NEW WING AT ROTHAMSTED.}

$\mathrm{N}$ Friday, June 27 , the new wing of the Rothamsted laboratories was opened by the Right Hon. Walter Runciman, President of the Board of Agriculture, in presence of a large and distinguished company, which included Earl Grey, Earl Denbigh, Earl culable benefit to the world, markedly increasing the yields of some of the British and Continental crops, and rendering possible the economic growth of wheat in Australia. Feeding experiments on animals came later, and proved of fundamental importance both to farmers and physiologists. During the fifty-seven years of their partnership, Lawes and Gilbert had investigated most of the important problems connected with British agriculture, and laid the whole community under a great debt of obligation to them. The work thus begun had expanded considerably under Mr. Hall's directorship (1902-12), and the growth was such that the new wing was already full, and the director, Dr. Russell, was preparing plans for new buildings to be erected in commemoration of the centenary of the birth of Sir John Lawes (18I4) and Sir Henry Gilbert ( 1817 ). Mr. Runciman expressed the hope that the centenary fund would be well and widely supported.

Mr. J. F. Mason, M.P., who followed, recognised that farmers had evolved an admirable system of agriculture, but pointed out that every industry benefited

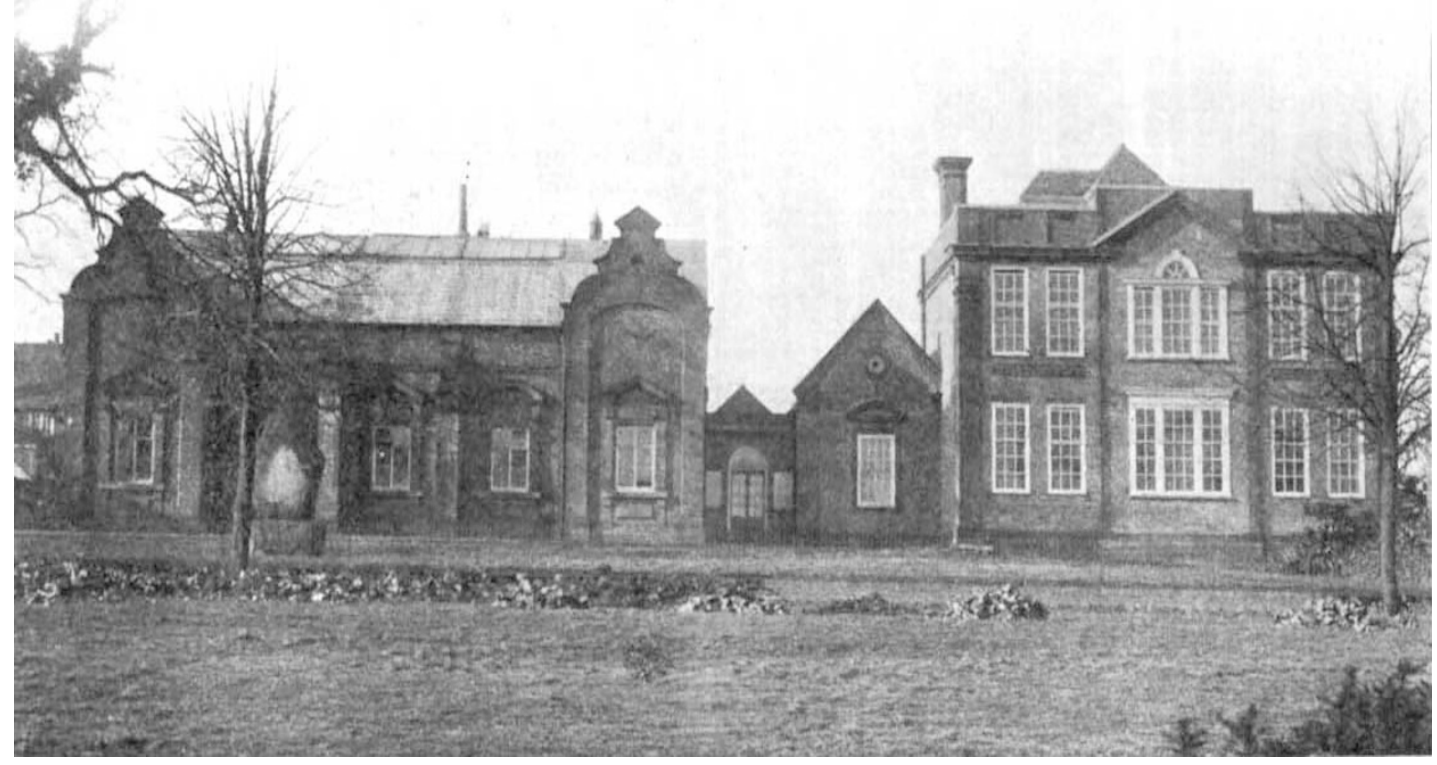

The new wing (on the right) adjoining the old one-storey building of the Rothamsted Experiment Station.

Rosse, Lord Lucas, Prof. H. E. Armstrong, Mr. G, W. Lamplugh, Dr. W. N. Shaw, Sir William Tilden, Sir David Prain, Dr. G. J. Fowler, Dr. J. A. Voelcker, and others.

In his opening remarks the chairman (Sir John Thorold) stated that the wing now ready for opening was the third great advance during the last few years at Rothamsted. The first was made in 1906, when Mr. J. F. Mason gave the James Mason Bacteriological Laboratory, and provided funds for its maintenance; the second was made in 1907 , when the Goldsmiths' Company gave a grant of ro,oool. towards soil investigations; and the third became possible when the Government instituted the Development Fund, out of which part of the cost of new buildings could be met.

In declaring the buildings open, Mr. Runciman sketched out the history of the Rothamsted Experiment Station from its beginning in 1843 to the present time. The experiments grew out of some pot trials made by Lawes as a young man in the late 'thirties. The first result was the discovery of superphosphate, which alone had proved of almost incalNO. 2279 , VOL. 9I] by scientific aid. He instanced the steel industry as one in which science had done great things. Already science had done much for agriculture, and there is every reason to suppose that it will do more.

Earl Denbigh and Sir Hildred Carlile both paid high tributes to the work that is being done at Rothamsted in relation to British agriculture, while Earl Grey emphasised the enormous part that has been played by science in the development of Canadian agriculture.

The buildings were then inspected. They include a large soil laboratory and directors' room on the ground floor, a botanical laboratory, library, and chemical laboratory on the first floor, and a glasshouse for water cultures on the roof. Special rooms are provided in the basement for polarimeter work and for soil incubations. The laboratory is served throughout with electric current, which is generated in an adioining dynamo and battery house. The total cost of the building and fittings is about $3400 l$., and the expenditure on the new farm (which has been taken over to supplement and extend the old experjmental fields) is about $3200 l$. Towards this the Board 
of Agriculture has made a grant of $3100 l$. out of the Development Fund, and has also promised an annual maintenance grant of $2500 l$. from the same source. These grants are made on the "pound for pound" principle, i.e. they are given subject to an equal amount being raised from other sources. The Society for the Extension of the Rothamsted Experiments was founded for the purpose of collecting subscriptions, and is now making a further appeal. Subscriptions and donations should be sent to the secretary, the Rothamsted Experiment Station, Harpenden.

It is hoped to raise 6oool. as the centenary .fund, and thus to qualify for a further grant of $6000 l$, making a total of $\mathrm{r} 2,000 l$, a sum which it is estimated will give buildings and appliances adequate for some years to come.

\section{THE GLASGOW MEETING OF THE}

\section{INSTITUTION OF NAVAL ARCHITECTS.}

THE Institution of Naval Architects held a successful and largely attended summer meeting in Glasgow on June $23^{-27}$. An interesting series of visits to works and excursions had been arranged, that to Messrs. Beardmore's shipyard, and the excursion to Arran with which it was combined, proving particularly enjoyable. While most of the papers dealt with purely technical matters, one or two were of more general interest.

In a paper on safety of life at sea, Mr. Hillhouse summed up the present state of affairs from the point of view of the naval architect. Apart from careful navigation the three factors on which we have to rely are wireless telegraphy, subdivision of hulls, and a sufficiency of boats. Of these, the adequate subdivision of hulls presents very serious constructional difficulties, and offers few advantages in the case of fire, while it is almost impossible to provide sufficient small boats and to guarantee that they shall all be usable in the moment of emergency. The one thing on which we can insist is careful navigation, although this may involve some reduction in speed.

Dr. S. J. P. Thearle directed attention to a number of cases in which cracks have developed in the sheil plating of a steel vessel at points removed from rivetholes and from the edges of the plate. These have been found to occur only in the vicinity of a frame unsupported by any beam, and are evidently due to "fatigue" following alternate stressing of the plate by "panting."

In a paper on the effect of form and size on the resistance of ships, Mr. J. S. Baker dealt with the effect of an increase in the length of the parallel portion of a vessel and of fullness of form. The problem was first attacked from a theoretical point of view on the assumption of stream-line flow; the distribution of pressure around the hull was computed; and a law deduced for the speed at which transverse wavemaking occurs. These results were compared with those obtained from model experiments, and from these the author deduces an expression for the most economic length of parallel body to be associated with a given entrance and run.

Prof. A. H. Gibson and Mr. Hannay Thompson read a paper dealing with the theory of "suction," or interaction between passing vessels, and with an extensive series of experiments carried out to investigate this important question. The vessels used were respectively $90 \mathrm{ft}$. and $30 \mathrm{ft}$. in length, displacing respectively 96 and $2 \cdot 6$ tons. The experiments were divided into two sets, one dealing. with the behaviour of the vessels when moving at different distances apart and at different speeds with helms lashed amidships, and the other dealing with the helm angles necessary to maintain a straight course and with the forces and moments operative to produce deflection of the course under similar conditions. The experiments were carried out in deep and open water, and the authors conclude that even in these circumstances interaction is a very real danger to navigation under certain conditions. The danger would appear to be greatest when the larger vessel is passing the smaller in fairly close proximity at a speed not greatly in excess of that of the smaller. In such circumstances, particularly if the larger be at the time accelerating with a view of drawing out of range of the smaller, the latter may be drawn into collision, except in so far as prevented by the helm, from distances as great as three or four lengths of this vessel. With the vessels within one length of each other the helm required to keep the smaller on its original course varied with its longitudinal position relative to the larger, and with their relative speeds. When all circumstances favoured interaction a helm angle of as much as $20^{\circ}$ was necessary to prevent collision. Generally speaking, since the helm effect increases somewhat more rapidly than that of suction, a vessel is more easily controlled against these forces at high than at low speeds.

An interesting paper by $\mathrm{Mr}$. A. Cannon records the results of experiments with an apparatus designed by Sir H. Biles on principles laid down by Colonel Russo, R.I.N., to investigate the effect of internal loose water upon the rolling of a ship amongst a regular series of waves, while a paper by Mr. Lloyd Woodward, dealing with the theory of the same subject, forms a useful supplement to this. The experiments point to the conclusion that, generally speaking, the addition of free water decreases the angle of roll, and always does so if its quantity is limited. If, however, the quantity is fairly large, and particularly in short and high waves, the effect is to increase the angle, and under a certain combination of wavelengths and height the angle may become dangerous. Further, these large angles are attained in a very few rolls, and it is quite possible for them to be attained in an actual ship, although the resistance to roll may be very great.

In a paper which was taken as read, Prof. L. Gümbel dealt with the cavitation of screw propellers, concluding that the tendency to cavitation not only increases with a diminution in the depth of immersion and with the amount of dissolved air in the water, but also depends very largely on the pitch of the propeller, on the angle formed by the feather edge in the cross section of the blade, and on the amount of slip. As regards the latter point, the limit of slip which may take place without cavitation is reduced as the speed of the vessel increases. On the other hand, the occurrence of cavitation is not dependent on the surface pressure over the blade area. A small angle at the emersion edge is more easily obtained with a broad-bladed propeller than in one with narrower blades. In this fact lay, in the author's opinion, the secret of the success that had been obtained with turbine screws with broad blades. Since, however, broad blades involve increased friction, an attempt should be made to so form the cross section as to get a narrow blade with the minimum possible angle of emersion.

Other papers descriptive of the results of trials on modern vessels propelled respectively by geared turbines and by Diesel engines enable an interesting comparison to be gained between the performance of these types of motor. In the turbine installation of 2400 b.h.p. the steam consumption was only $12.551 \mathrm{~b}$. per shaft h.p., the ratio of effective h.p. to shaft h.p. attaining a maximum value of about $5^{8}$ per cent. at No. 2279 , VOL. 9I] 